\title{
As Mudanças nas Regras da Aposentadoria. Os Postos de Trabalho Estão Adaptados à População que Envelhece?
}

\section{Carlos Alberto Diniz Silva}

Médico do Trabalho e ergonomista

Ex-Médico do Trabalho da DRT/São Paulo

Pesquisador associado ao Laboratório de Ergonomia do Departamento de Engenharia de Produção - UFMG

Palavras-chave: Ergonomia, Aposentadoria, Envelhecimento

\section{RESUMO}

As mudanças nas regras de aposentadoria apontam para uma maior permanência dos idosos no mercado de trabalho. Esta permanência só se tornará viável caso haja mudanças nos postos de trabalho, tornando-os mais flexíveis e compativeis com as caracteristicas de uma população que envelhece. A partir de análises ergonômicas são apontadas algumas direções de pesquisas para a melhoria das condições de trabalho: concepção de dispositivos tẻcnicos e organizacionais baseada na análise do trabalho real e uma política de formação contínua que permita aos trabalhadores permanecerem em atividade dentro do contexto atual de inovaç̃̃es tecnológicas.

\section{ABSTRACT}

The changes observed on the rules of retirement point out the increasing of the elderly's stay on the market. This stay will only be viable if there are also changes at the work stations, making them more flexible and compatible with the characteristics of a population that ages. Ergonomic analysis point out some directions of researches that can contribute to the improvement of work conditions: confections of technical and organizational provisions based on the analysis of the work how it's truly done and a politics of continuous formation that allows workers to stay actives on the actual context of technological innovations. 


\section{A Seguridade Social e o Envelhecimento da População Brasileira}

Há muito debate-se a crise da seguridade social no Brasil e em vários outros países. Tem-se como certo que se tornou impossível assegurar ao aposentado um ganho mensal que possibilite sua sobrevivência caso sejam mantidas as regras atuais. A expectativa de vida tem aumentado $\mathrm{e}$ a proporção entre o número de empregados na ativa que contribuem para a seguridade social e o número de aposentados tem decaído progressivamente, em razão do aumento desses últimos.

"Estima-se que a esperança de vida ao nascer, no final'do século, aproxime-se dos 67 anos no Brasil e, no período de 2020 a 2025, dos 72 anos" e que "a população de 60 anos ou mais estimada para 1990 para todo o Brasil é de 7,1\% da população total, de $8,3 \%$ no ano 2000 , de $10,0 \%$ em 2010 e de $15,1 \% \mathrm{em} 2025$. Ou seja, projeta-se para 2025 uma população de 34 milhões de pessoas com 60 anos ou mais" (NEUPERT, 1987 citado por CAMARGO \& SAAD, 1990: 13 e 17). O censo de 1991 confirma as previsões: $7,4 \%$ da população brasileira tem 60 anos ou mais, sendo que os homens contribuem com $6,8 \% \mathrm{e}$ as mulheres $7,9 \%$ (FUNDAÇÃO IBGE, 1993).

Estima-se que, atualmente (1990), a população de 60 anos ou mais, no Brasil esteja próxima de 10 milhões de habitantes, número que deixa o país entre os $10 \mathrm{com}$ maior população de idosos do mundo. Espera-se que, no início do próximo século, esta venha a ser a sexta do mundo. Em números relativos, no entanto, o Brasil apresenta um percentual de idosos bastante inferior ao dos paises mais desenvolvidos, onde, em sua maior parte, no início da década de 80 , já ultrapassavam os $15 \%$ da população, ou mesmo os $20 \%$, como nos casos da Suécia, Inglaterra, Dinamarca e República Federal da Alemanha. (NAÇÕES UNIDAS, 1986 citado por CAMARGO \& SAAD, 1990:20)

Não pretendemos discutir aqui a validade da argumentação econômica proposta como solução. Vamos supô-la correta. O que pretendemos discutir é a sua viabilidade: o aumento da idade mínima para se requerer a aposentadoria e o tempo mínimo de contribuição à seguridade social. Ou seja, os trabalhadores irão permanecer por mais tempo no mercado de trabalho e, conseqüentemente, os postos de trabalho serão ocupados por una mão-de-obra mais idosa. Independentemente das dificuldades que analisaremos a seguir, que inviabilizam a permanência dos idosos no mercado de trabalho, devemos antes de tudo refletir sobre a contradição em termos da solução proposta. Num país onde já há desemprego entre jovens, qual o sentido de manter os mais idosos na ativa? A solução pode resultar em uma mera condenação ao desemprego.

Analisando "o comportamento da população economicamente ativa (PEA) no Brasil, PAIVA (1986) destaca a significativa 
diminuição da taxa de atividade entre os homens mais velhos a partir de 1950 . E aponta que, em relação a padrões internacionais, os níveis de participação são baixos, já nos grupos de 40-49 e 50-59 anos", pois no "ano de 1980 , em países como a Malásia e a Tailândia, $57 \%$ dos homens de 60 anos ou mais, estavam Incluídos na PEA; entre as mulheres, os percentuais eram de $22 \%$ na Malásia e $31 \%$ na Tailândia (PAGTOULUN-AN, 1989). No Brasil, nesse mesmo ano, essas porcentagens eram de $44 \%$ e $7 \%$, respectivamente para os homens $e$ as mulheres." (CAMARGO \& YAZAKI, 1990: 6)

"As razões sugeridas para a diminuição das taxas de atividade também em idades mais avançadas são, entre outras, a maior cobertura da previdência social e a queda relativa das atividades agrícolas. Destacam-se, no entanto, as dificuldades que as pessoas idosas encontram no mercado de trabalho: a existência de uma grande massa de trabalhadores mais jovens competindo por empregos faz com que uma parte dos mais velhos seja colocada à margem da produção." (CAMARGO \& YAZAKI, 1990:66)

Esta marginalização tem aumentado com o passar do tempo pois se "em 1950 cerca de $83 \%$ dos homens com idade de 60 a 69 anos e $57 \%$ daqueles com 70 anos e mais apareciam como economicamente ativos, três décadas depois esses percentuais haviam se reduzido para $58 \%$ e 22\%, respectivamente. Entre as mulheres, as taxas eram bem menores: $7,8 \%$ para as de 60-64 anos e 4,6\% para as de 70 anos e mais, em 1950, passando para $10,6 \%$ e 2,8\% em 1980 (PAIVA, 1986)." (CAMARGO \& YAZAKI, $1990: 66$ )

O idoso não é inativo por indolência pois onde há oferta de emprego, como na agricultura, a taxa de atividade aumenta. No meio rural paulista, as taxas de atividade são mais elevadas, com a absorção de $17 \%$ das pessoas de 60 anos e mais ocupadas do Estado, embora, na PEA, representem apenas $10 \%$ do total. $73,0 \%$ dos homens na área rural, entre 60-69 anos, mantêm-se ocupados contra apenas $46,1 \%$ na área urbana. Na faixa de 70 anos e mais as taxas são de $32,8 \%$ e $14,5 \%$, respectivamente. (CAMARGO \& YAZAKI, 1990:67)

Essa migração tende para ocupações mais compativeis com suas possibilidades, no caso da agricultura onde, apesar do grande esforço físico, as exigências de rapidez são menores: “... em 1980 vê-se que aumenta a ocupação nas atividades do setor primário conforme cresce a idade: entre os homens maiores de 70 anos do interior, mais de $50 \%$ estavam ocupados na agricultura. Comportamento diverso ocorria com as pessoas empregadas em atividades industriais, pois, da população masculina com 60 a 64 anos da Grande São Paulo, representavam $37 \%$, diminuindo para $26 \%$ após os 70 anos, com o que os serviços e o comércio ganhavam maior representatividade (indício de que, com a idade, fica mais difícil manter-se em ocupações formais)." (CAMARGO \& YAZAKI, 1990: 69) 


\section{PRODUÇÃO}

De fato "a saída relativamente "precoce" do mercado de trabalho não significa, amparo adequado. Significa, ao contrario, ausência de programas de retreinamento, condições precárias de higidez, deficiências educacionais acumuladas e outras desvantagens com relação à população mais jovem que compete, com vantagens, no estreito mercado de trabalho. Significa, por outro lado, ingressar numa situação social estigmatizada e precária, onde conseguir um novo trabalho é difícil, senão impossivel; onde a possibilidade de adquirir novas habilidades, recapacitandose para o trabalho numa nova fase da vida, é irrealizável; ..." (FARIA, 1990: 261)

Nossa exposição irá abordar três tópicos:

- primeiro, a concepção dos meios de trabalho requer análises mais acuradas da atividade humana pois ela ainda é mal conhecida e as condições de sua execução freqüentemente superestimam as reais capacidades dos trabalhadores;

- segundo, se à medida que envelhecem, os trabalhadores têm dificuldades crescentes em ocupar postos com grandes exigências de força física como também os que demandam precisão e rapide $z^{1}$ como nas linhas de montagem e trabalho repetitivo em geral, sua permanência em atividade requer uma organização do trabalho mais flexivel e,

- finalmente, as inovações tecnológicas, principalmente com a introdução da informática, têm acarretado dificuldades ligadas à simbolização e à abstração crescentes requerendo, portanto, uma política de formação contínua que capacite a todos a ocupação dos novos postos de trabalho.

Nossa argumentação pretende fazer um alerta sobre o fato de que uma solução técnico-econômica simplista corre o risco de ser inviabilizada na prática, caso não sejam tomadas medidas e correções paralelas que permitam aos mais idosos permanecer no mercado de trabalho, condenado-os ao subemprego ou, mais perversamente, ao desemprego e à perda da seguridade social.

Em resumo, embora seja incontestável o fato de que esteja havendo um aumento da expectativa de vida, não necessariamente a população trabalhadora está em perfeitas condições de saúde que permitam a sua permanência no mercado de trabalho.

É dificil avaliar as causas de exclusão do mercado de trabalho baseando-se em estatísticas no Brasil. As patologias diagnosticadas pelos médicos em consultórios nem sempre fazem alusão a causas incapacitantes para o trabalho atendo-se a uma nosologia de causa imediata: gripe, resfriado, hipertensão etc. A partir das estatísticas de mortalidade também não se pode inferir a morbidade dos idosos que dificulta o exercício do trabalho pois a causa do óbito quase nunca está relacionada a problemas ósteoarticulares, do sono, nervosismo, 


\section{PRODUÇÃO}

incapacidades de seguir cadências, diminuição da força muscular etc. Pesquisa francesa em indústria automobilística mostra que, após 40 anos, 60 a $70 \%$ dos trabalhadores apresentam uma deficiência reconhecida pelos médicos (BUET, 1983 citado por TEIGER, 1989).

Em parte, as más condições de saúde são derivadas da própria atividade de trabalho cuja concepção dos meios e da organização nas quais ela é exercida não respeita as características psicofisiológicas dos seres humanos, como veremos a seguir. Um reflexo das atuais condições de trabalho pode ser medido pela alta porcentagem de aposentadorias por invalidez. Segundo a pesquisa nacional por amostra de domicílios - PNAD 1983 (citada por PRATA, 1990: 215) as aposentadorias por invalidez apareciam com $36,1 \%$, por velhice $36,3 \%$ e por tempo de serviço $27,6 \%$.

Queremos deixar claro que não acreditamos que o trabalho seja inelutavelmente penoso e que se deva ficar inativo o mais rápido possível. Nossa posição é a de que o trabalho exerce um papel importante na estruturação da personalidade e, se bem adaptado, pode ser fonte de prazer contribuindo para a auto-estima. Inegavelmente assegura a todos o reconhecimento social e fortalece a sensação de ser-no-mundo.

\section{A Concepção dos Meios de Trabalho Requer Análises da Atividade Real}

Desde a separação radical entre concepção e execução do trabalho no início deste século a partir das idéias de Taylor, os trabalhadores perderam a capacidade de influir na escolha do seu espaço de trabalho e de suas ferramentas, bem como, no gerenciamento do tempo alocado às tarefas. Este divórcio entre concepção e execução tem gerado situações danosas à integridade física e mental da população trabalhadora.

DANIELLOU et alii (1989), a partir de análises do trabalho em diversos ramos da produção, enfatizam o desconhecimento que se tem das verdadeiras dificuldades que os trabalhadores enfrentam no desempenho de suas atividades. Muito freqüentemente a carga de trabalho é subestimada. Tarefas aparentemente simples a um observador desatento podem exigir do operador um volume intenso de microdecisões por unidade de tempo, o que denominamos de sobrecarga cognitiva, acompanhada de sobrecarga física localizada (por exemplo: a empunhadura e movimentação contínua de uma ferramenta).

Tomando como exemplo os resultados da análise da atividade real em uma linha de montagem de televisores, os citados autores relacionam os fatores que influenciam na gênese da sobrecarga cognitiva. Realizando operações de montagem em tempos estritamente determinados pela gerência de métodos, os operadores se vêem confrontados a situações variáveis a cada ciclo: conserto de grampos tortos, ajuste de abertura de dois grampos, separação de diversos elementos misturados etc. A cada variação 


\section{PRODUÇÃO}

o operador deve tomar uma decisão e isto dentro do tempo exíguo de ciclos que, às vezes, não duram mais que quinze segundos. Estes pequenos incidentes não são levados em conta quando se faz a determinação do tempo gasto na operação. Todo o trabalho é organizado como se não houvesse variação nem das ferramentas nem da matéria prima nem do próprio estado interno do operador (deve-se manter a mesma postura rígida e fixa durante toda a jornada de trabalho independentemente da fadiga muscular). Soma-se então à fadiga nervosa (pelas microdecisões) a fadiga física.

Neste ponto gostaríamos de esclarecer o que entendemos por análise da atividade real. Com este termo denominamos a análise dos atos realizados pelo operador em situação real de trabalho para atingir os objetivos de sua tarefa que foi planejada e organizada por outras instâncias hierárquicas. A atividade real pode ou não coincidir com a atividade prescrita, ditada, imposta. Esta diferença ocorre porque o operador tenta ajustar o seu modo operatório às variações sempre presentes da matéria prima (um grampo com fio torto), das ferramentas (perda de corte em ferramenta cortante) e do seu próprio estado interno (mudança de postura para descansar certos grupos musculares). A eficácia da adoção de modos operatórios menos custosos, obtidos graças à experiência, vai depender da flexibilidade permitida pela organização e pelos meios de trabalho. Assim, se a altura de um plano de trabalho em que se exige a percepção visual de pequenos detalhes foi concebida apenas para a postura sentada, 0 operador terá pouca possibilidade de executá-lo em pé quando sentir dores nas costas pois sentirá dificuldade em enxergar o detalhe.

Para ilustrar a importância da análise da atividade real vamos comentar o trabalho de ORTALE (1995) sobre as atividades de um operador de ponte rolante.

\subsection{A Concepção de uma Ponte Rolante} Não Leva em Conta as Exigências Visuais da Tarefa

O trabalho é dividido em duas operações. A primeira consiste em manobrar duas conchas que retiram gesso de um caminhão e o deposita sobre um monte. A segunda, em retirar gesso do monte e colocá-lo em recipientes (tremonhas) destinados à produção.

A cabine da ponte foi concebida corretamente para que o operador ficasse sentado em cadeira com apoio para as costas. A face anterior da cabine é de vidro permitindo uma boa visão em frente. Os comandos manuais das conchas foram colocados corretamente para seu manuseio pelos membros superiores. Foram respeitados os estereótipos naturais e os ângulos de conforto para os membros superiores. As manobras podem ser realizadas com os membros em posição de exercer a força muscular máxima. Mas isto apenas e somente se o operador permanecer na posição sentada. 


\section{PRODUÇÃO}

A análise da atividade real mostrou que, para exercer o controle visual sobre as conchas, o operador adotava a postura sentada mas tinha que permanecer com o tronco inclinado para a frente durante toda a jornada. Isto porque as conchas, na maior parte do tempo, ficam em baixo da cabine e não em frente. Nessa nova postura (a única que permite visualizar as conchas) os comandos ficam afastados dos membros superiores e, conseqüentemente, estes operam totalmente fora das angulações de conforto.

Essa análise foi realizada porque o operador tinha sido afastado várias vezes, sob licença médica, por lombalgias. Acrescente-se que o operador, por exercer função terceirizada, tinha grande temor de ser demitido o que o levava a procurar o médico apenas quando as dores se tornavam insuportáveis. O quadro doloroso impedia o correto controle da ponte. Foi evidenciado pela análise que o operador deveria exercer um minucioso controle das alavancas para que as conchas não atingissem seres humanos nem fios de alta tensão e tampouco a proteção de vidro da cabine, além de um certo cuidado para não dispersar o pó de gesso no ambiente o que tornaria mais dificil o controle visual.

Ora, se a analista se ativesse apenas à análise da situação idealizada e prescrita pelo conceptor (o operador trabalhando sentado e apoiando as costas), poderia concluir apressadamente que o posto de trabalho obedecia às normas de conforto e interpretar as lombalgias como um problema individual. A análise da atividade real e o levantamento minucioso das exigências da tarefa (principalmente as exigências visuais e a pressão por rapidez da parte dos caminhoneiros que gostariam de ter seus caminhões esvaziados o mais depressa possivel) permitiram evidenciar porque o operador adotava a posição sentada mas com o tronco inclinado para a frente.

É fácil concluir que se os conceptores de pontes rolantes não levarem em conta as exigências da tarefa, continuarão a projetar pontes inadequadas. Os operadores não conseguirão ocupar o posto por tempo prolongado, perdendo todo o saber acumulado (executar as manobras com segurança e rapidez máximas) e terão de suportar a sensação de fracasso individual. Na melhor das hipóteses irão engrossar as estatísticas dos aposentados por invalidez devido a lombalgia.

Um outro exemplo de concepção baseada em hipóteses falsas pode ser retirado da análise da atividade real de postos de lavagem de panelas em cozinhas industriais.

\subsection{A Concepção de Cozinhas} Industriais Não Prevê a Lavagem de Utensilios Pesados e Volumosos

Investigando dez cozinhas industriais de grande porte ( 10.000 ou mais refeições/ dia), algumas em hospitais de alto padrão recém-construídos, verificamos que a área mais crítica era considerada a da lavagem 


\section{PRODUÇÃO}

de utensílios pesados e volumosos. Quase sempre era oferecido algum prêmio para o trabalhador que se dispusesse a ocupar esse posto. Sua dificuldade consistia em ter que adotar posturas incômodas (agachado, ajoelhado ou com o tronco fletido para frente e para baixo) para que fossem adequadamente removidas as crostas aderidas provenientes da cocção. $E$ isso em utensílios apresentando saliências e depressões pelo uso e grandes superfícies se encontrando com ângulo reto.

Ora, os arquitetos conceberam o posto de lavagem a partir da hipótese de que ela seria realizada como em uma cozinha domiciliar. Seria suficiente apenas a projeção em escala maior. Conservou-se a estrutura de uma cuba e fonte de água fixadas à parede.

Na realidade, essa pia nunca é utilizada. Ou o utensílio é grande demais para caber na cuba ou seu peso torna inviável a sua manipulação para expô-lo à fonte de água. Do mesmo modo, a altura da pia torna difícil o alcance às partes mais profundas do utensílio. Sem exceção, todos os trabalhadores optaram por fazer a lavagem colocando-os sobre o piso numa tentativa de aliviar a fadiga muscular decorrente da contração estática prolongada caso tenham que sustentar o seu peso. Para o enxágüe utiliza-se a estratégia de acoplar uma mangueira à torneira. Assim procedendo, o trabalhador pode executar sua tarefa rodeando o utensílio, diminuindo o tempo em que deve levantálo. Em nove cozinhas, esse modo operatório foi reconhecido pelas chefias tendo sido permitido colocar um suporte (mesa) para apoio do utensílio, o que eleva o plano de trabalho e evita a postura agachada ou ajoelhada.

Baseando-se nas próprias soluções encontradas pelos trabalhadores, os arquitetos poderiam facilmente conceber esse posto tornando-o menos penoso: a adoção de uma mesa central que permitisse o acesso por qualquer lado, de preferência com altura regulável, e o fornecimento de água através de uma fonte elástica e móvel vinda do teto (igual a um "chuveirinho").

Mas parece que a concepção nunca é precedida de um levantamento completo das especificidades locais. Parece também que os arquitetos nunca retornam ao local para verificar os resultados práticos de seus projetos. Senão, veriam essas inadequações. Acrescentamos que a construção ou reforma de cozinhas em São Paulo é quase sempre realizada por uma mesma empreiteira, reputada altamente competente. Nossa pergunta é: muito tempo seria gasto se a concepção fosse precedida de uma análise das atividades? Talvez não, se considerarmos o tempo infinitamente maior a que os trabalhadores se submeterão a posturas penosas. ${ }^{2}$

Elaborando hipóteses falsas ou insuficientes a partir dessa realidade mal conhecida, os responsáveis pela concepção dos ambientes, das máquinas, dos equipamentos e pela organização do trabalho, produzem situações em que as características psicofisiológicas dos 


\section{PRODUÇÃO}

trabalhadores não são respeitadas. A inadequação, por sua vez, leva a um abandono do posto de trabalho, seja por parte da empresa que dispensa o operador incapaz de atender às exigências de precisão e rapidez, seja por parte do trabalhador que se demite pela excessiva fadiga física e mental. Tal fenômeno leva a repercussões negativas para a empresa (alta rotatividade, absenteísmo, baixa qualidade do produto etc.), para o trabalhador (fadiga física e mental, sensação de fracasso, desemprego) e para a sociedade (sobrecarga na assistência médica e encargos financeiros com inválidos).

O absenteísmo e a rotatividade elevados podem mesmo ser tomados como indicadores de rejeição às más condições de trabalho como assinala WISNER (1987: 33).

No próximo tópico abordaremos algumas situações de trabalho em que predominam as atividades altamente repetitivas $^{3}$ com grandes exigências de precisão e rapidez e suas conseqüências para os trabalhadores: as lesões por esforços repetitivos e a alta rotatividade. Se neste primeiro tópico abordamos uma situação com ênfase na disposição física do posto de trabalho, no próximo daremos destaque ao papel importante que desempenha a organização do trabalho.

\section{Por uma Organização do Trabalho Mais Flexível}

O grande tema atual é a competição capitalista pela maior eficiência econômica, ou seja, fabricar produtos com custos cada vez menores. É claro que todos nós estamos interessados nessa eficiência pois, em tese, permitiria o acesso de todos aos bens de consumo. No entanto, precisamos encarar o outro lado da moeda: quase sempre a redução dos custos de produção é conseguida graças à intensificação do ritmo de trabalho e à extrema parcelização das tarefas. Em tese, a parcelização garante um aprendizado rápido e uma pronta substituição da mãode-obra frente ao desgaste precoce dos trabalhadores.

Mas usando as próprias palavras de LUTTWAK (1995), um cientista político e historiador romeno radicado nos EUA e trabalhando no departamento de defesa, a "busca da eficiência a todo custo e o excesso de competição entre empresas estão moendo as pessoas. Existe a noção absurda de que o livre comércio, a competição aberta entre indivíduos, nações e empresas, é a única forma de capitalismo. Esse determinismo é irmão gêmeo das certezas da esquerda no passado. O ritmo perturbador do capitalismo está acabando com os valores mais preciosos" entre eles citamos a cooperação.

A competição está moendo as pessoas. Certas atividades, pelas suas exigências de precisão e rapidez, excluem rapidamente uma parcela considerável da mão-de-obra. Assim é que (DANIELLOU et alii, 1989) constatam que na França "se é velho:

- aos 40-45 anos na indústria automobilística (clássica); 


\section{PRODUÇÃO}

- aos 30-35 anos na indústria eletrônica;

- aos 25-30 anos na confecção (de roupas)."

A exigência de rapidez não pode explicar por si só a exclusão e o envelhecimento precoce. Deve-se mencionar o grande papel desempenhado pelo trabalho em turno ou trabalho noturno fixo. ${ }^{4}$ Mas a exigência de rapidez agrava 0 peso de todos os outros fatores desfavoráveis.

Dentro da nossa realidade brasileira, citaremos dois estudos realizados por nós em São Paulo, dos quais extrairemos os dados da população trabalhadora referentes à estrutura de idade e à antigüidade na empresa.

Partimos da hipótese de que, caso as exigências das tarefas sejam compatíveis com as possibilidades da maioria da população, não importando o sexo ou a idade, iremos encontrar amostras representativas de todas as faixas de idade, numa distribuição igual à da população economicamente ativa (PEA). Se as exigências da tarefa forem compativeis apenas com as características psicofisiológicas de jovens, veremos, num estudo da população que executa esta tarefa, uma super-representação da faixa etária mais jovem e uma sub-representação das faixas de idade mais avançadas, se as compararmos às da PEA.
A figura 1 mostra a distribuição percentual da PEA da Grande São Paulo (PEA/GSP) e as populações empregadas em um hospital geral, em uma montadora de tratores, em uma empresa de processamento de dados e a população de operadores de checkouts (caixas) de dez mercados. A figura 2 destaca as diferenças entre a porcentagem de trabalhadores em cada faixa etária, em determinado setor, e a porcentagem em cada faixa correspondente à PEAVGSP que foi tomada como zero.

Podemos notar que nas faixas etárias inferiores a 25 anos, a população de empregados em empresa de processamento de dados e aquela de operadores de checkouts estão super-representadas em relação à PEA/GSP, ou seja, há mais trabalhadores jovens nessas empresas que o esperado a partir da PEA. Já as faixas a partir dos 30 anos estão sub-representadas (valores negativos no gráfico).

Já a população do hospital e da montadora de tratores é quase que representativa da PEA (valores próximos de zero). Isto não quer dizer que nessas duas últimas todos os setores possam absorver pessoas de todas as idades pois as estatísticas referem-se. a sua população geral. Quando se faz um estudo populacional comparando-se diferentes setores podem ser verificadas enormes diferenças. 


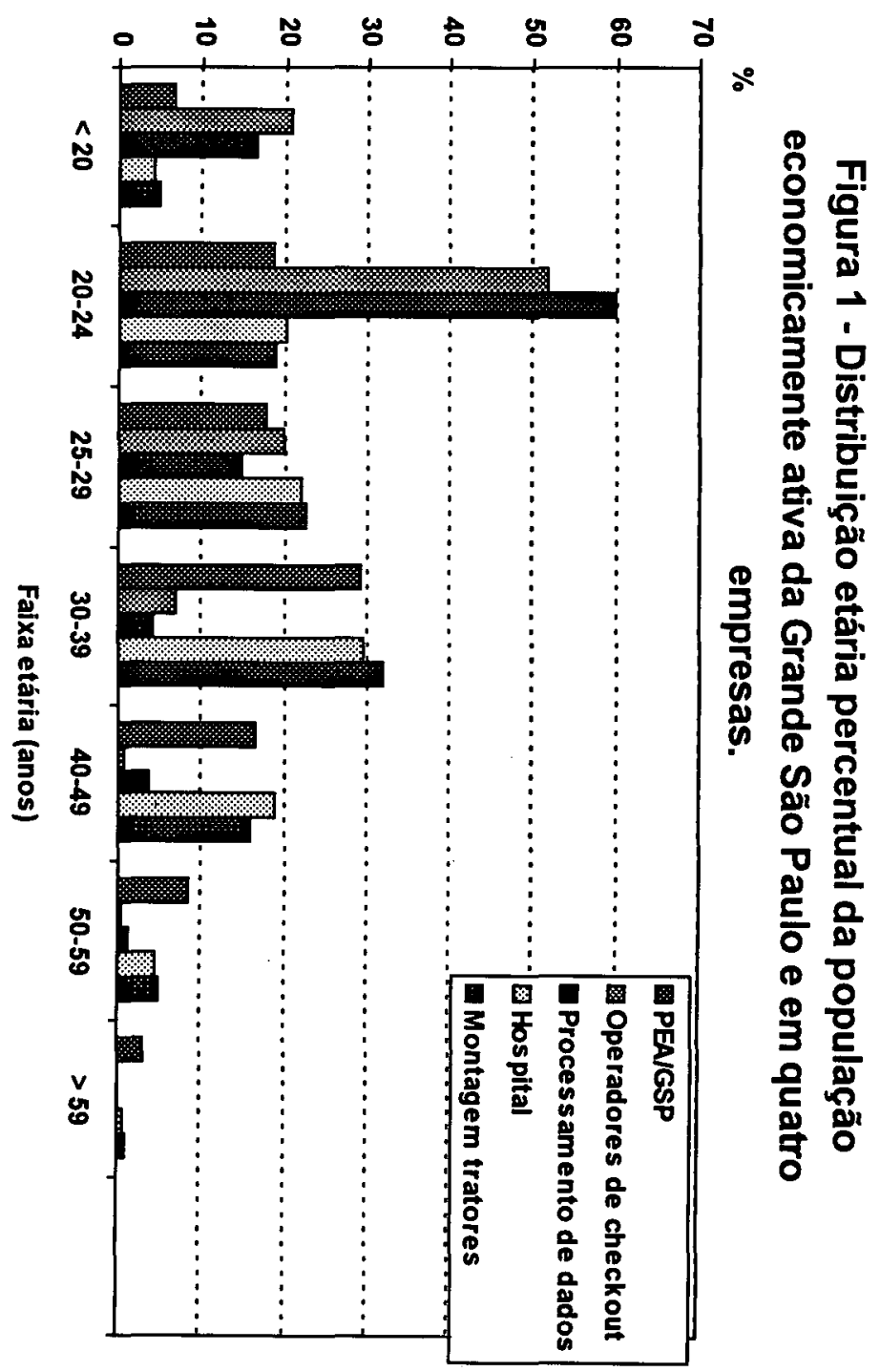




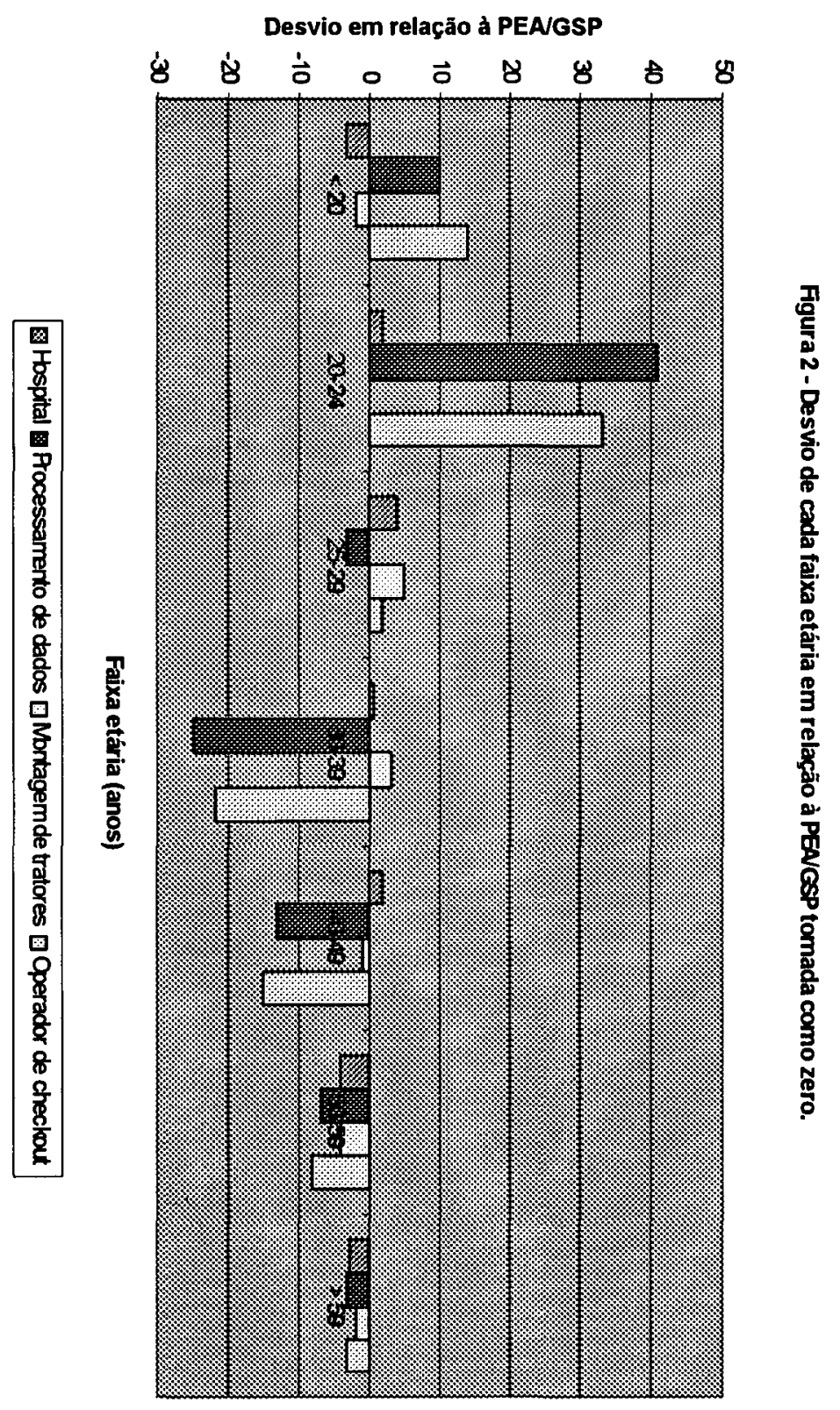




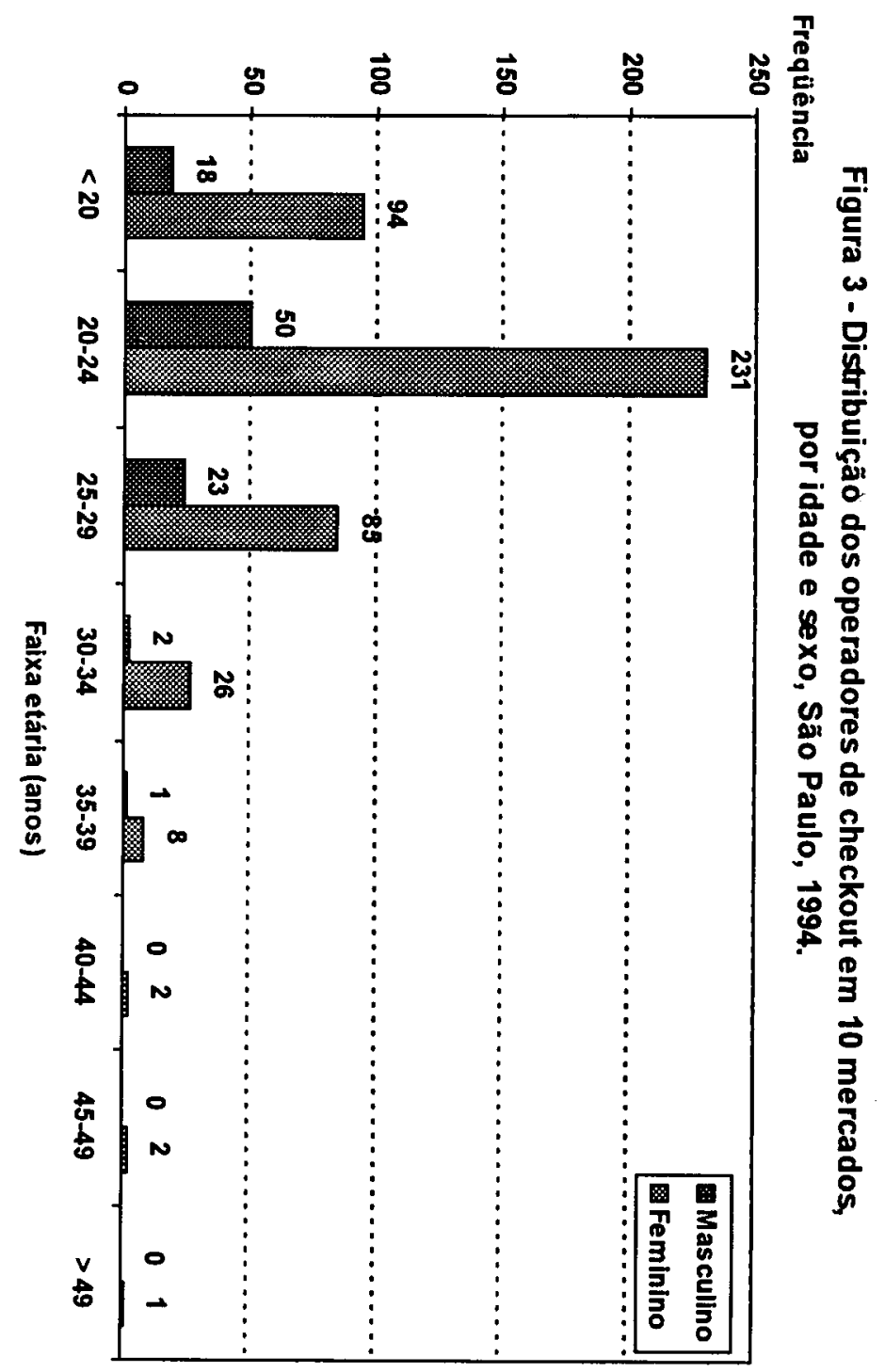




\section{PRODUÇÃO}

Figura 4 - Distribuição percentual dos operadores de checkout em 10 mercados, por idade e sexo, São Paulo, 1994.

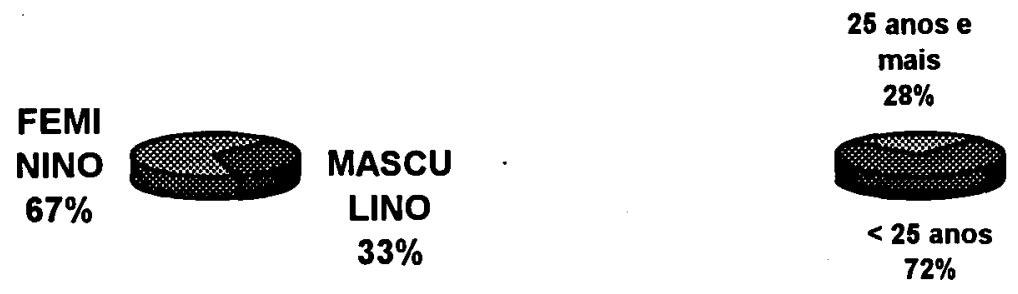

Figura 5 - Antiguildade dos operadores de checkout em 10

Freqüência mercados, por sexo, São Paulo, 1994.

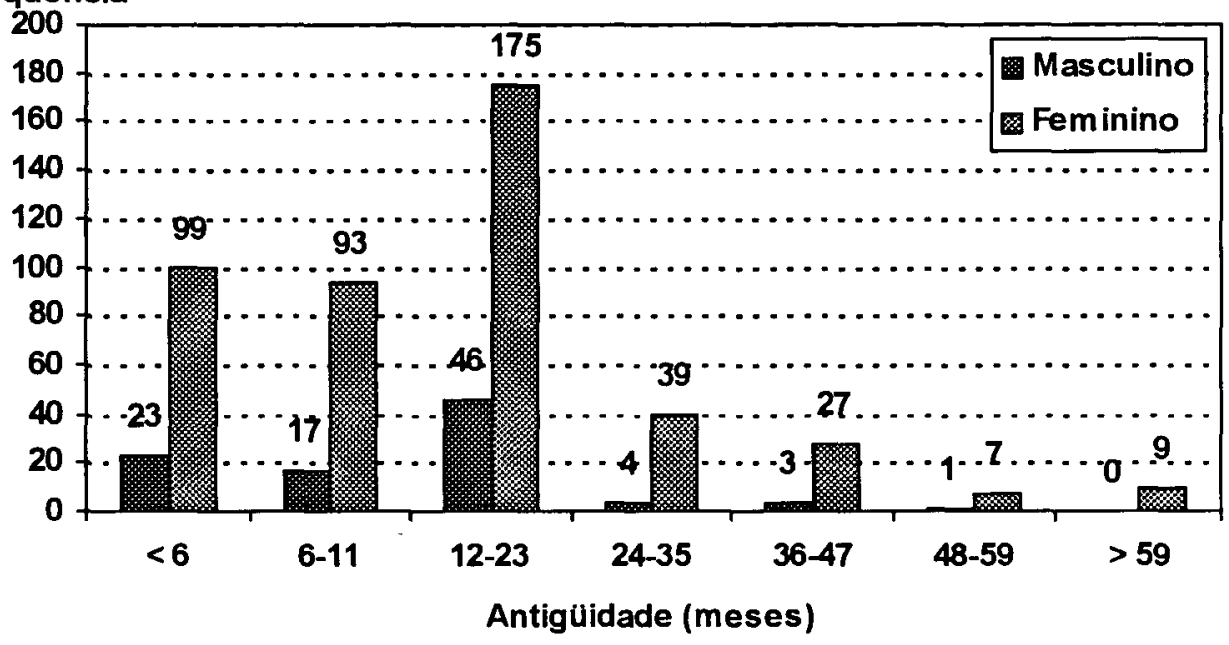




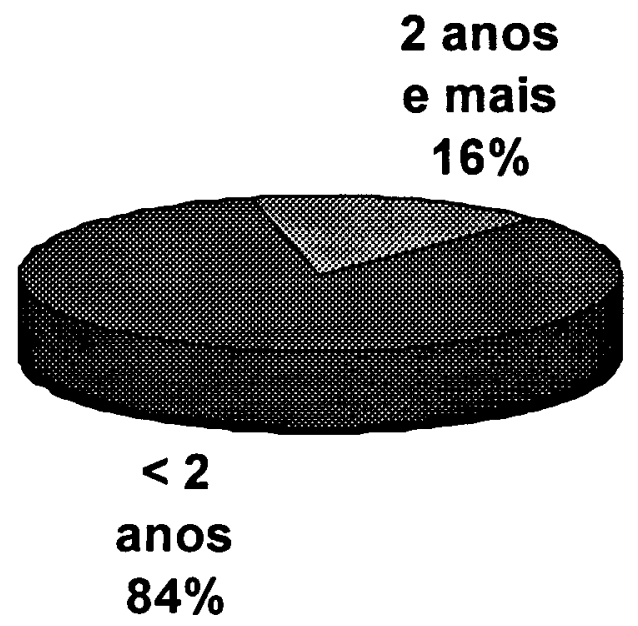

Figura 6 - Antiguidade dos operadores de checkout em 10 mercados, São Paulo, 1994.

A seguir, abordaremos alguns aspectos da situação dos operadores de checkouts. Por uma questão de economia não entraremos em todos os detalhes sobre os fatores que podem influenciar no aparecimento das lesões por esforços repetitivos: peso das mercadorias manipuladas, disposição física dos checkouts etc. Vamos nos ater a algumas particularidades da organização do trabalho. Esse exemplo foi escolhido pois contempla uma patologia cada vez mais freqüente no $\mathrm{Brasil}^{5} \mathrm{em}$ cuja gênese está fortemente implicada a participação da organização do trabalho. Por outro lado é uma patologia que afeta precocemente ${ }^{6} \mathrm{o}$ sistema ósteo-músculo-articular, justamente o sistema que mais suscita dificuldades aos idosos no desempenho de suas tarefas.

\subsection{A Atividade Parcelizada E rígida dos Operadores de Checkout}

A pesquisa (DINIZ \& FERREIRA JR, 1994) foi realizada em 1994 a partir de uma demanda do Ministério Público devido a numerosas queixas de Lesões por Esforços Repetitivos originárias dessa atividade. Foram pesquisados dez mercados, escolhidos aleatoriamente mas respeitando a inclusão obrigatória de uma amostra que abrangesse desde micromercados até hipermercados. Os dados sobre a população (idade e antigüidade) referemse a todos os operadores de checkout dos dez mercados, totalizando 543, conforme lista fornecida pelo Departamento de Pessoal. Os outros dados foram obtidos através de questionários anônimos, com respostas de 79 operadores de checkout, escolhidos aleatoriamente. 
A seguir discutiremos alguns dos nossos resultados.

a) Trata-se de uma população predominantemente feminina e jovem (Fig. 3 e 4 ): dos 543 operadores, $449(82,7 \%)$ eram do sexo feminino, sendo que 393 de ambos os sexos $(72,3 \%)$ tinham menos de 25 anos de idade. ${ }^{7}$

b) É grande a rotatividade (Fig. 5 e 6): $83,4 \%$ dos operadores têm antigüidade menor que 2 anos. Ou seja, mesmo os jovens não conseguem suportar as exigências da tarefa.

c) É alta a incidência de dor e fadiga muscular: $\mathbf{7 7 \%}$ dos operadores referiram dor ou fadiga muscular em pelo menos uma das seguintes regiões durante a última semana de trabalho: costas $(40 \%)$, braços (36\%), coluna vertebral $(31 \%)$, ombros (26\%), pernas (21\%), mãos ( $18 \%$ ), punhos (15\%), nuca (13\%), pescoço (13\%) e quadris $(4 \%) .92,4 \%$ dos operadores referiram ter sentido fadiga muscular ou dor em pelo menos uma daquelas regiões desde que passaram a desempenhar a atual tarefa. Enfatizamos que trata-se de dor referida pelo trabalhador e que não são necessariamente casos diagnosticados como Lesões por Esforços Repetitivos. Há uma ilusão de que as inovações tecnológicas têm contribuído para a diminuição da carga fisica de trabalho. Embora a carga fisica de trabalho geral possa realmente diminuir, a extrema parcelização das tarefas leva a uma sobrecarga localizada, acarretando dores em determinados grupos musculares.

O checkout de mercados tem passado por transformações tecnológicas. A mais recente tem sido a introdução da leitura óptica que visa primordialmente a aceleração do atendimento ao cliente. A leitura óptica ao invés de diminuir a carga de trabalho têm contribuído para o aumento do número de queixas de dores nos membros superiores segundo a impressão dos gerentes, fato não demonstrável por falta de dados comparativos. Porém, estudos americanos (HARBER et alii 1992; MARGOLIS \& KRAUS, 1987) confirmam essa impressão. Eles apontam o aumento do risco de lesões dos membros superiores com a introdução de scanners com leitura óptica "pelo aumento do número de itens checados e a diminuição da diversidade das atividades de trabalho." Isto foi verificado em nosso estudo: com a introdução da leitura óptica o mercado pôde atender a um maior número de clientes. Os gerentes relatam que houve, em média, um aumento de $30 \%$ nas vendas. Com exceção de micromercados, em todos os outros os operadores de checkout exerciam apenas e exclusivamente esta função.

d) A jornada de trabalho oscilava em torno de 44 horas semanais, à exceção de 3 mercados, onde havia jornada de 6 horas diárias perfazendo um total de 36 horas semanais. Além das pausas de 1 hora para refeição e 15 minutos para lanche, não se observou qualquer outro sistema de pausas vigorando formalmente. Na maioria dos mercados, principalmente nos de médio e grande porte, qualquer saida do 


\section{PRODUÇÃO}

operador do seu posto de trabalho deveria ser autorizada pelo fiscal ou encarregado de caixa, pois muitas vezes implicava em fechamento contábil do caixa. Em poucas situações ocorrem horas extras, entretanto, as jornadas de $\mathbf{4 4}$ horas semanais são esquematizadas de modo a garantir o máximo de horas nos dias de pico (sábado), quando a jornada chega a atingir ou ultrapassar 10 horas de trabalho, reduzindo-se a jornada diária das $2^{\text {as }}$ às $6^{a s}$ feiras.

Esta jornada prolongada está em íntima relação com o aparecimento de dores musculares conforme relatado pelos operadores. Os gerentes confirmam-na dizendo que o absenteísmo aumenta logo após jornadas mais extensas.

Em nenhum dos mercados de médio e grande porte, os operadores alternam as tarefas de caixa registradora com outras, entretanto, além da tarefa especifica de registro de mercadorias, também foi observado como fazendo parte do trabalho do operador, em maior ou menor escala: pesagem de mercadoria, ensacamento de material frágil ou perecível, verificação de preço, atenção contra furtos, limpeza da bancada, observação e controle da fila de espera, verificação do correto preenchimento de cheques ou contagem do dinheiro, cálculo do troco, auxílio no ensacamento.

Dentro da perspectiva dessa exposição, ou seja, a de que os postos de trabalho não estão adequados a uma população que envelhece, vamos destacar alguns aspectos deste estudo.

A primeira é que os proprietários e gerentes dos estabelecimentos pesquisados relataram que valorizam na contratação dos operadores: a assiduidade, a pontualidade, a honestidade e destacam sobremaneira a polidez e a delicadeza no trato com os clientes. Estão cientes de que essas qualidades têm mais chances de serem encontradas em pessoas mais maduras. No entanto, acabam optando pelos mais jovens na tentativa de encontrar trabalhadores que não adoeçam muito. Sabem que a atividade é desgastante e referem que um operador suporta permanecer nessa atividade por, no máximo, quatro anos.

Um argumento que se ouve freqüentemente quando se busca entender o fenômeno da alta rotatividade é que certas atividades com as de entrada de dados e operadores de checkout são apenas para início de carreira e que, independentemente das condições de trabalho, a rotatividade vai ser sempre alta. Nossa pergunta sem resposta é: em quantas atividades se emprega o mesmo raciocínio? Esta população que já apresenta sinais de desgaste, alguns até em graus mais avançados de Lesões por Esforços Repetitivos, vai conseguir ocupar outros postos de trabalho menos exigentes? Quais?

Sabemos que a adaptação dos postos aos mais idosos é difícil e uma prova disto é que mesmo os países há mais tempo industrializados estão se desfazendo de indústrias de montagem que requerem alta 
repetitividade e transferindo-as para paises recém-industrializados. Foi o que aconteceu nos EUA que venderam sua última fábrica de televisores aos coreanos. Alegam que agora optam por vender idéias (Revista VEJA. 26/7/95. p. 104). Mas o fato é que os EUA, berço de Taylor e Ford, não são mais competitivos devido aos altos salários e principalmente porque sua população, com alto nível de escolaridade, rejeita o trabalho penoso ou de pobre conteúdo. Os países que não podem sustentar sua economia apenas com a exportação de idéias ou tecnologia devem fazer o quê?

\section{As Inovações \\ Tecnológicas Requerem uma Política de Formação Contínua}

Não há nenhuma política de formação contínua no Brasil. As mudanças nas formas de executar o trabalho (cada vez mais informatizado) pode deixar à margem um grande número de trabalhadores não tão idosos mas que, por falta de hábito, talvez não consigam freqüentar cursos de reciclagem ou desenvolver raciocínios mais abstratos para lidar com máquinas que cada vez mais se distanciam da realidade imediata. A temperatura passa a ser um número e não mais o calor sentido diretamente no corpo.

É compreensível que haja grande dificuldade para se sentar novamente em bancos escolares após várias décadas em que o trabalho se resumiu a executar ordens. Preocupados com a situação, os paises industrializados têm adotado politicas de formação contínua, ou seja, periodicamente os trabalhadores freqüentam cursos mesmo que não tenham relação direta com a atividade que desenvolvem, o objetivo sendo apenas $o$ de manter por toda a vida a sensação de segurança de que se pode sempre aprender, a não perder a desenvoltura de lidar com papel e caneta e, mais importante, o exercício constante de raciocínio abstrato.

Ora, se estamos enfrentando os mesmos problemas de caixa da Seguridade Social que enfrentam os países industrializados, não podemos simplesmente copiar as soluções econômicas que eles têm adotado. Impõem-se também adotar as políticas que permitam ao idoso permanecer no mercado de trabalho.

As soluções não são simples: nem no Brasil nem nos países do primeiro mundo. Como consequêencia da inadequação dos postos à população que envelhece "bem antes da aposentadoria, muitas pessoas idosas ficam desempregadas. E uma vez despedidos, eles não conseguem mais colocar-se novamente. Na Bélgica e no Reino Unido, segundo um relatório da Organização Internacional do Trabalho, feito em 1955, os desempregados que haviam permanecido sem trabalho por vinte e quatro meses tinham, em média, mais de 50 anos. Não existe necessariamente ligação entre a 


\section{PRODUÇÃO}

importância do desemprego e as aptidões. Os trabalhadores sem qualificação e os operários especializados são os mais atingidos, mas também, em virtude da modernização da ferramentaria, os cargos de alta qualificação são suprimidos; os jovens monopolizam os trabalhos de escritório, abandonando aos homens de idade as tarefas penosas e insalubres. Estes são obrigados a baixar suas exigências, no que diz respeito ao salário, à natureza $\mathrm{e}$ às condições de trabalho. Muitas vezes não se resignam a isso imediatamente; quando acabam por renderse, estão econômica, social e moralmente debilitados." (BEAUVOIR, 1990: 279-80).

Mesmo quando não são despedidos os trabalhadores que não suportam mais as fortes exigências de tempo são remanejados dentro da empresa acabando por cumprir tarefas de limpeza, manutenção e jardinagem, tarefas que eventualmente demandam grande esforço físico mas onde as cadências são menos impostas (VOLKOFF, 1989).

Os desempregados mais idosos que procuram emprego enfrentam sérias dificuldades devido ao preconceito que nossa sociedade desenvolve contra os idosos. " $A$ priori, os empregadores desconfiam das pessoas idosas: isso salta aos olhos, quando se examinam as ofertas de emprego. Em quase todos os países, o limite de idade estipulado vai de 40 a 45 anos. Segundo uma pesquisa feita em 1963 em oito grandes cidades dos EUA, um quinto dos serviços de seleção de emprego fixavam o limite de idade aos 35 anos, e um terço aos 45 anos. Na França, em 41.000 ofertas de emprego estudadas ao longo de uma pesquisa, $30 \%$ visavam pessoas de menos de 40 anos, $40 \%$, pessoas de 20 a 29 anos, $30 \%$, pessoas de 50 a 65 anos. Nos jornais americanos, $97 \%$ dos anúncios fixam como limitc 40 anos." (BEAUVOIR, $1990: 279)^{8}$

Os dois preconceitos mais freqüentes com respeito aos idosos se referem à resistência à mudança $\mathrm{e}$, no campo da aprendizagem especificamente, à lentidão nas respostas e à diminuição na capacidade de memorização imediata.

A resistência à mudança de postos de trabalho e à introdução de novas tecnologias é um fenômeno ambivalente observado freqüentemente e origem de fortes preconceitos não só em relação aos idosos mas a todos os trabalhadores. Dai que, por ocasião de mudanças significativas nos processos de trabalho, os empregadores prefiram fazer dispensas em massa e contratar mão-de-obra mais jovem e "sem vicios." Essa política tem uma dupla desvantagem. Para alguns o desemprego e para a empresa a perda da competência e de todo um saber acumulado que, muitas vezes, nem a introdução de novas tecnologias consegue superar. Muito se queixa da baixa qualificação profissional dos trabalhadores brasileiros, mas perguntamos: a eles é dado tempo suficiente e condições favoráveis para que desenvolvam sua competência máxima?

A resistência à mudança "é em geral considerada muito negativamente e 


\section{PRODUÇÃO}

atribuída a uma rigidez de caráter, a uma falta de espírito de empresa, de gosto do risco, que seriam características da mentalidade dos operários e, sobretudo, das operárias... Ora, estudando mais a fundo, descobre-se que a resistência à mudança não está relacionada a um sentimento de satisfação atual, mas sim estreitamente associada à intensidade da carga de trabalho e mais particularmente aquela que representou a aprendizagem da tarefa no posto atualmente ocupado. Em geral, são os operadores que mais tiveram dificuldades em atingir o ritmo exigido os mais apegados a sua função: tudo se passa como se as dificuldades encontradas para se alcançar a cadência constituíssem uma experiência tão desagradável, que teme-se revivê-la, pois sabe-se que toda mudança implica uma readaptação, que leva tempo e aumenta a carga de trabalho em razão da atividade mental suplementar exigida pelo aprendizado." (DANIELLOU et alii, 1989)

No que diz respeito ao fato de os idosos necessitarem de mais tempo em novas aprendizagens e $o$ déficit de memória imediata LAVILLE (1989), em levantamento bibliográfico sobre a questão nos informa que: "Neste campo de reflexão, pode-se situar os problemas de formação em função da idade que desenvolve PACAUD (1971); enquanto que o jovem registra os conhecimentos propostos, o idoso tem necessidade de compreender e de tudo compreender a cada etapa, o que supõe um ritmo mais lento da formação; enquanto que o jovem aprende a teoria sem se colocar questões sobre as bases desta teoria e sobre sua aplicação, o idoso tem necessidade de explicação sobre os fatos e os raciocinios que conduzem a esta teoria, ele tem necessidade de compreender sua lógica; enquanto que o jovem pode aprender conhecimentos isolados, o idoso tem necessidade de ligar o que aprende ao que ele já sabe; como notam PERLMUTTER et cols. (1982) a propósito da memória, o que difere entre jovens e idosos, não é tanto a capacidade de memorização mas a capacidade de reter na memória os elementos com os quais não se sabe o que se fará. $O$ envelhecimento não é necessariamente fator de declínio profissional durante o período da vida ativa: são as escolarizações curtas, as formações não adaptadas, o conteúdo, a organização e as condições materiais de execução das tarefas que provocam esse declínio quando o operador idoso é avaliado em relação a uma norma estabelecida sobre uma população jovem."

Enfim, os mais idosos não tem necessariamente mais dificuldades para realizar uma tarefa mas sim de executá-la dentro das condições impostas pela organização do trabalho (TEIGER, 1989).

\section{Conclusões}

Caso queiramos resolver satisfatoriamente esse grave problema que vai se delineando em nossa sociedade é necessário um esforço conjunto. Ele nos afeta a todos. Será uma realidade em breve mesmo para os mais jovens. As soluções encontradas como o aumento da idade mínima para requerer a aposentadoria, 


\section{PRODUÇÃO}

aumento do tempo de contribuição e planos privados de complementação da aposentadoria não devem nos tranqüilizar a ponto de neglicenciarmos a procura de soluções mais satisfatórias.

A tendência progressiva de diminuição da taxa de fecundidade faz com que cada vez menos exista uma mão-de-obra jovem fartamente disponível e apta a ocupar os postos de trabalhos muito exigentes. As indústrias manifestam a tendência de se estabelecerem em cidades do interior, numa tentativa de distanciamento de sindicatos mais combativos. Mas já temos recebido alunos em nossos cursos de prevenção das Lesões por Esforços Repetitivos, provenientes destas cidades, onde já é preocupante o esgotamento dessa mãode-obra.

O plano de ação mundial sobre o envelhecimento, sob os auspicios da ONU (1982, citado por CAVALCANTI \& SAAD, 1990: 176-8), traçou diretrizes que destacamos entre outras:

- o conhecimento das tendências demográficas prevalecentes; ${ }^{9}$

- a educação da população em geral sobre o processo de envelhecimento e suas prováveis conseqüências, tanto para $o$ individuo como para a sociedade;

- a necessidade de que as pessoas de idade percebam alguma renda, seja por seu próprio trabalho, seja por transferência; e, mais especificamente dentro do nosso campo de ação:
- a implementação de programas que promovam uma imagem positiva do processo de envelhecimento;

- a necessidade de reciclagem e de adaptação de maquinários, além de horários de trabalho flexíveis.

Em resumo, não é inexorável a exclusão dos trabalhadores que envelhecem ou que apresentam alguma deficiência. É possivel sua permanência caso os postos de trabalho estejam mais de acordo com suas capacidades, que a organização do trabalho seja mais flexível e que a aprendizagem de novas tarefas thes seja adaptada.

Recebido em: 21/10/97

Recebido após revisão: 06/04/98

Aceito em: $22 / 04 / 98$

Publicado em: 27/07/98

\section{Referências Bibliográficas}

BARREIRA, Thaís Helena de Carvalho. Abordagem ergonômica na prevenção da LER. Rev. Bras. S. Ocup. 22(84):51-60, out./dez. 1994

BEAUVOIR, Simone de. $A$ velhice. Tradução da ed. francesa de 1970 por Maria Helena Franco Monteiro. $1^{a}$ ed. Rio de Janeiro, Nova Fronteira, 1990.

BRASIL. Ministério do Trabalho. 
Secretaria de Segurança e Saúde no Trabalho. Norma Regulamentadora 17: manual de utilização. Brasília, MTb/ SSST, 1994. 163 p. Técnico responsável: Carlos Alberto Diniz.

BUET, J. Les ouvriers âgés et les conditions de travail. Rapport interne du Service central des Conditions de travail RVI, Lyon, 1983.

CAMARGO, Antonio Benedito Maragone \& SAAD, Paulo Murad. A transição demográfica no Brasil e seu impacto na estrutura etária da população. In: FUNDAÇÃO SISTEMA ESTADUAL DE ANÁLISE DE DADOS (SP). O idoso na Grande São Paulo. São Paulo, SEADE, 1990. (Coleção realidade paulista) p. 9-39

\& YAZAKI, Lúcia Mayumi. Características demográficas e sócio-econômicas da população idosa. In: p. 42100

CAVALCANTI, Maria das Graças P. de H. \& SAAD, Paulo Murad. Considerações preliminares e o Plano de Ação Mundial sobre o Envelhecimento. In: 174-9

CUNHA, Carlos Eduardo Gouvea da; QUEIROZ, Pollyana Soledade; HATEM, Thamira de Paula; GUIMARÃES, Vladimir Yuri Monteiro. Lesões por esforços repetitivos: revisão. Rev. Bras. S. Ocup. 20(76): 47-59, 1992.

DANIELLOU, François; LAVILLE,
Antoine; TEIGER, Catherine. Ficção e realidade do trabalho operário. Rev. $S$. Bras. Ocup. 17(68):7-13, out./dez. 1989.

DANIELLOU, François. $L$ 'impact des technologies nouvelles sur le travail en postes dans l' industrie automobile. Paris, Laboratoire d'Ergonomie et de Neurophysiologie du Travail du Conservatoire National des Arts et Métiers, 1982.

DINIZ, Carlos Alberto; ROCHA, Lys Esther; FERREIRA JR. , Mário. Exclusão e reinserção profissional entre portadores de lesões por esforços repetitivos. In: CONGRESSO DA ASSOCIAÇÃO NACIONAL DE MEDICINA DO TRABALHO, $8^{\circ}$. Salvador, 1993. Anais. Tema livre. p. 83

DINIZ, Carlos Alberto \& FERREIRA JR, Mário. Sintomas músculo-esqueléticos e fadiga nos operadores de checkouts de mercados: uma abordagem ergonômica. São Paulo, 1994 (mímeo)

FARIA, Vilmar E. Conclusões. In: FUNDAÇÃO SISTEMA ESTADUAL DE ANÁLISE DE DADOS (SP). O idoso na Grande São Paulo. São Paulo, SEADE, 1990. (Coleção realidade paulista) p. $251-62$

FUNDAÇÃO INSTITUTO BRASILEIRA DE GEOGRAFIA E ESTATISTICA - IBGE. Anuário Estatistico. Rio de Janeiro, IBGE, 1993.v. 53 
HARBER, Philip; PENA, Laura; BLAND, Gerard; BECK, John. Upper extremity symptoms in supermarket workers. Am J Ind Med 22:873-84, 1992

KOSKELA, R S. Ocupational mortality and morbidity in relation to selective turnover. Scand. J. of Work Environ. Health, 8, Suppl. I, 1992. p. 34-9

LAVILLE, Antoine. Vieillissement et travail. Le Travail humain. Paris, 52(1):3$20,1989$.

LUTTWAK, Edward Nicolae. O risco do fascismo. VEJA. São Paulo, 14 jun. 1995. Entrevista. p. 7-9

MARGOLIS, Wendy \& KRAUS, Jess F. The prevalence of carpal tunnel syndrome symptoms in female supermarket checkers. JOccup Med. 29:953-56, 1987

NAÇÕES UNDAS. Perspectivas de la población mundial - estimaciones $y$ proyecciones en 1982. Nova York, NAÇÕESUNIDAS, 1986.

NEUPERT, R.F. Nova projeção da população brasileira: hipóteses baseadas em informações recentes. In: WONG, L.L.R. et alii. Futuro da população brasileira: projeções, previsões e técnicas. Embu, Abep. 1987.

ORTALE, Renata Landucci. Análise da atividade do operador de ponte rolante em depósito de gesso. Apresentado no Seminário de Ergonomia da FUNDACENTRO. São Paulo, abr. e jun./ 95 (mimeo)
OS ASIÁTICOS levaram tudo. VEJA. São Paulo, 26 jul. 1995. Economia \& Negócios. p. 104

PACAUD, Suzanne. Quelques cas concrets illustrant les difficultés ou les facilités que l'âge entraîne dans la formation professionnelle des travailleurs. L'information psychologique, 44, 92105, 1971

Le travailleur vieillissant: quelques reflexions sur ses difficultés, mais aussi ses facilités d'adaptation au travail. In: LAVILLE, Antoine; TEIGER, Catherine; WISNER, Alain (orgs.). Age et contraintes de travail. Jouy-en-Josas, NEB, 1975. p. 115-79

PAGTOLUN-AN, I. Growing old in Philippinas. Belo Horizonte, dez. 1989. (mimeo)

PAIVA, P.T.A. Cinqüenta anos de crescimento populacional e absorção de mão-de-obra no Brasil: 1950 a 2000 . Revista Brasileira de Estudos da População. Campinas, (3):63-86, jan./jun. 1986

PERLMUTTER, M. \& MITCHELL, D.B. The appearance and disappearance of age differences in adult memory. In: CRAIK, F.I.M. \& TREHUB, S. (eds). Aging and cognitive processes, Plenum Press, 1982. p. $127-44$

PRATA, Lizete Emilia. Os idosos face aos benefícios previdenciários. In: 
FUNDAÇÃO SISTEMA ESTADUAL DE ANÁLISE DE DADOS (SP). O idoso na Grande São Paulo. São Paulo, SEADE, 1990. (Coleção realidade paulista) $\mathrm{p}$. 207-31

SATO, Leny et alii. Atividade em grupo com portadaores de L.E.R. e achados sobre a dimensão psicossocial. Rev. Bras. S. Ocup. 21(79): 49-62, jul./.set. 1993.

TEIGER, Catherine. Le vieillisimente différentiel dans et par le travail: un vieux probléme dans un contexte récent. Le Travail humain. Paris, 52(1): 21-56, 1989.

VOLKOFF, Serge. Le travail après cinquante ans: quelques chiffres et plusieurs inquiétudes. Le Travail humain. Paris, 52(2): 97-116, 1989.

WISNER, Alain. Por dentro do trabalho: ergonomia: método \& técnica. $1^{a}$ ed. São Paulo, FTD/Oboré, 1987.

\section{Notas}

' Denominamos exigência de rapidez, de tempo ou pressão temporal a obrigatoriedade de cumprir a tarefa ou parte dela em um tempo imposto seja por uma máquina semi-automática ou uma linha de montagem que se desloca continuamente ou em situações onde o salário é pago por peça produzida ou onde a tarefa tem que terminar em horário determinado ou onde haja pressão por parte de usuários. Em resumo, em toda e qualquer situação onde o trabalhador deve executar a tarefa em um tempo não determinado por ele.

${ }^{2}$ Os interessados em maiores detalhes sobre concepção de cozinhas poderão se reportar a BRASIL (1994: 31-89)

${ }^{3}$ Os escandinavos consideram uma atividade altamente repetitiva: "quando as atividades são cumpridas em no máximo 30 segundos (ciclo de trabalho igual ou menor do que 30 segundos) ou quando a realização da atividade requer a repetição de padrões de movimentos similares por mais de $50 \%$ do ciclo de trabalho (ciclo fundamental é realizado por mais de $50 \%$ do ciclo total de trabalho)." (citado por BARREIRA, 1994)

${ }^{4} \mathrm{O}$ trabalho em turnos alternantes ou noturno fixo torna-se crítico em torno de 40 anos. Em uma empresa automobilística francesa constatou-se que o número de trabalhadores após esta idade vai decaindo progressivamente nos postos submetidos a horários em turnos ou noturno fixo ao passo que aumenta naqueles com horário diurno fixo. No entanto, esta mobilidade é possível apenas em empresas de grande porte com diversidade de postos mas ela é acompanhada quase sempre de perda de qualificação e redução salarial (DANIELLOU, 1982).

${ }^{5} \mathrm{Em} 1987$ e 1988 as lesões por esforços repetitivos foram as patologias mais freqüentemente diagnosticadas $(40,95 \% \mathrm{e}$ $41,77 \%$ respectivamente) pelo Núcleo de Coordenação de Saúde do Trabalhador (NUSAT) no Grupamento Médico-Pericial 


\section{PRODUÇÃO}

de Acidente do Trabalho em Belo Horizonte. Houve uma queda para 20,83\% em 1989 (CUNHA et alii, 1992).

6 Os portadores de LER são predominantemente jovens. Em São Paulo dos 402 casos atendidos no Programa de Saúde do Trabalhador da Zona Norte, $70,2 \%$ tinham menos de 35 anos, sendo $20,7 \%$ entre 18 e 25 anos, $49,5 \%$ entre 25 e 35 e $22,4 \%$ entre 35 e 45 (SATO et alii, 1993). Em Belo Horizonte 36,3\% dos portadores tinham entre 20 e 29 anos e $45,5 \%$ entre 30 e 39 (CUNHA et alii, 1992).

${ }^{7}$ Estes dados estão de acordo com TEIGER (1989) que, apoiada nas pesquisas do Ministério do Trabalho da França de 1984 , afirma que a porcentagem de mulheres operárias submetidas a uma exigência de ritmo automática aumentou (de 28,6\% em 1978 para 29,3\% em 1984) enquanto que para os homens diminuiu (de $14,3 \%$ para $13,1 \%$ ); entre as operárias, são as não qualificadas as que suportam as exigências mais intensas pois um terço delas estão submetidas a um ritmo automático com repetitividade que em $20 \%$ dos casos tem um ciclo de trabalho inferior a um minuto. Essas diferenças entre homens e mulheres são mais acentuadas nas faixas etárias mais jovens.

${ }^{8}$ BEAUVOIR não faz a referência da fonte de seu material pois seu livro é endereçado ao público leigo. No entanto, a seriedade da autora é indiscutível.
9 A procura de dados deve ser fomentada tanto dentro das empresas com estudo de distribuição por idade e sexo, bem como, antigüidade, comparando os diversos setores, como também com pesquisas nacionais mais amplas. 